\title{
An Intradiscal Granuloma Due to a Retained Wooden Foreign Body
}

\author{
Mehmet Arif Aladag, M.D., Mehmet Akif Durak, M.D. \\ Department of Neurosurgery, Inonu University School of Medicine, Medical Faculty, Malatya, Turkey
}

We report a patient with a wooden foreign body granuloma in the intervertebral disc space being symptomatic 17 years after a paraspinal penetrant trauma. According to the our result of the search for wooden foreign body granulomas, this is the first case suffered from a wooden foreign body granuloma in the intervertebral disc space that reported in the literature. In this report, we emphasized the importance of rigorous examination and follow up in paraspinal wooden penetrant traumas.

Key Words : Spinal injuries · Intervertebral disc · Granuloma · Foreign-body.

\section{INTRODUCTION}

Retained foreign body granulomas in the intervertebral disc space due to penetrant traumas are very rare like other paraspinal ones ${ }^{2,3,5-7,10)}$. To our knowledge, all of the reported retained foreign bodies in the intervertebral disc space were from missile injuries and there was not any report involving a retained foreign body granuloma in this region from wooden penetrant trauma ${ }^{2,3,5,6,10)}$.

\section{CASE REPORT}

A 30-year-old man sought medical care with a history of low back pain (LBP) that radiated to lower extremities. He reported that he had fallen from a tree and a tree branch had been penetrated into him left lower back before 17 years. That tree branch had been taken out manually and he had recovered without any complaint. In the past two months, the patient has presented a LBP radiating to his lower limbs. Physical examination revealed a bad-healed scar at about level of the third lumbar vertebra on left paraspinal region (Fig. 1). He had pain on lower back with palpation. The characterization of the pain in his lower extremities was a dermatomal pattern. The straight-leg-raising sign was negative and there was not any neurologic deficit on lower limbs.

Computerized tomography (CT) demonstrated a hypodense lytic lesion in the L4 vertebral body surrounding a linear hyperdense structure (Fig. 2). Anterior part of the disc space between fourth and fifth lumbar vertebrae had disappeared with fusion of these bodies in magnetic resonance (MR) images. MR images also revealed a lesion that lodged in posterior part of this disc space and expanding into the corpuses of these vertebrae (especially into L4 vertebral corpus). This lesion was hypointense in

- Received : December 2, 2014 •Revised : March 16, 2015 •Accepted : March 18, 2015

- Address for reprints : Mehmet Arif Aladag, M.D.

Department of Neurosurgery, Inonu University School of Medicine, 44315 Malatya, Turkey

Tel : +90-422 3410660 / 3202, Fax : +90 4223410729 , E-mail : marifaladag@hotmail.com

This is an Open Access article distributed under the terms of the Creative Commons Attribution Non-Commercial License (http://creativecommons.org/licenses/by-nc/4.0) which permits unrestricted non-commercial use, distribution, and reproduction in any medium, provided the original work is properly cited. 


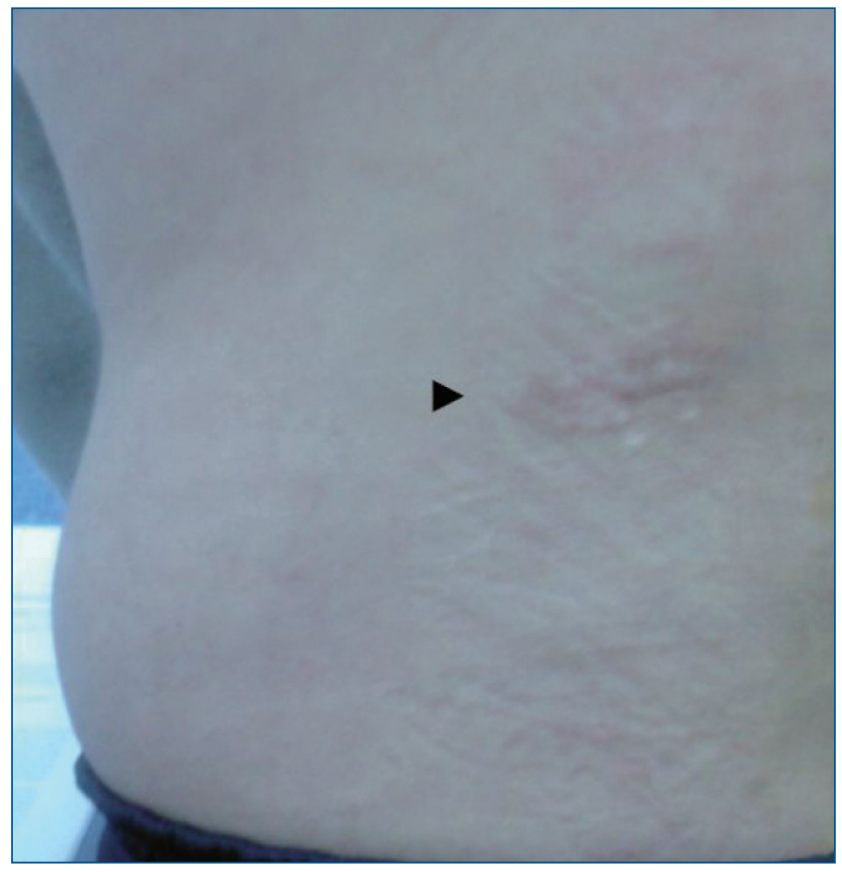

Fig. 1. Clinical appearance of bad-healed scar on left lower back.

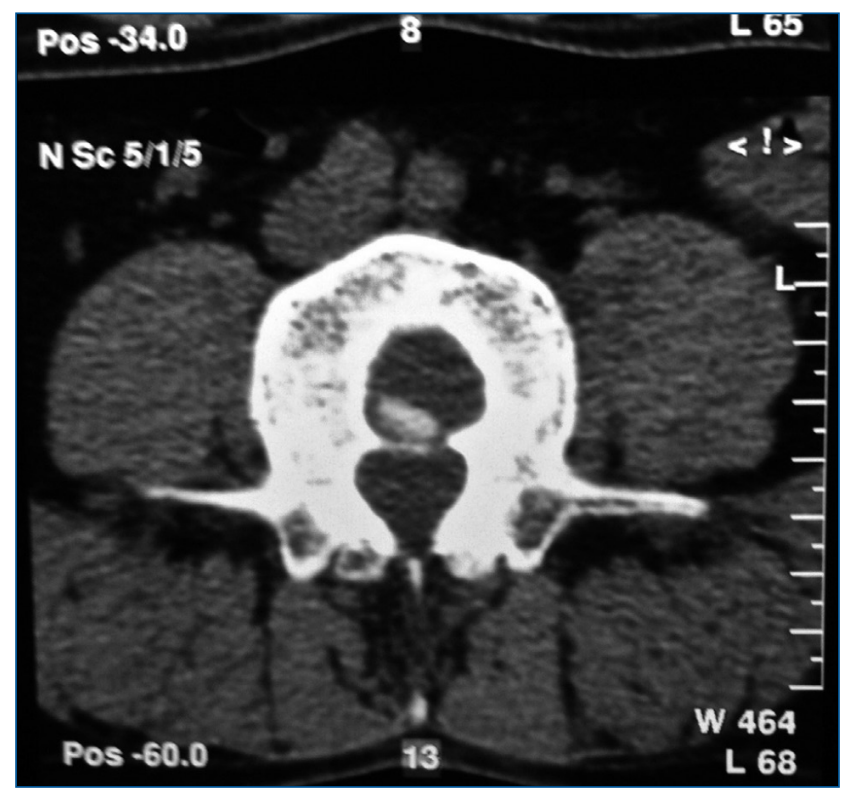

Fig. 2. Axial CT slice at the level according to $L 4$ vertebral upper end plate. It is seen a hypodense lesion surrounding a linear hyperdense structure in the vertebral corpus. CT : computed tomography.
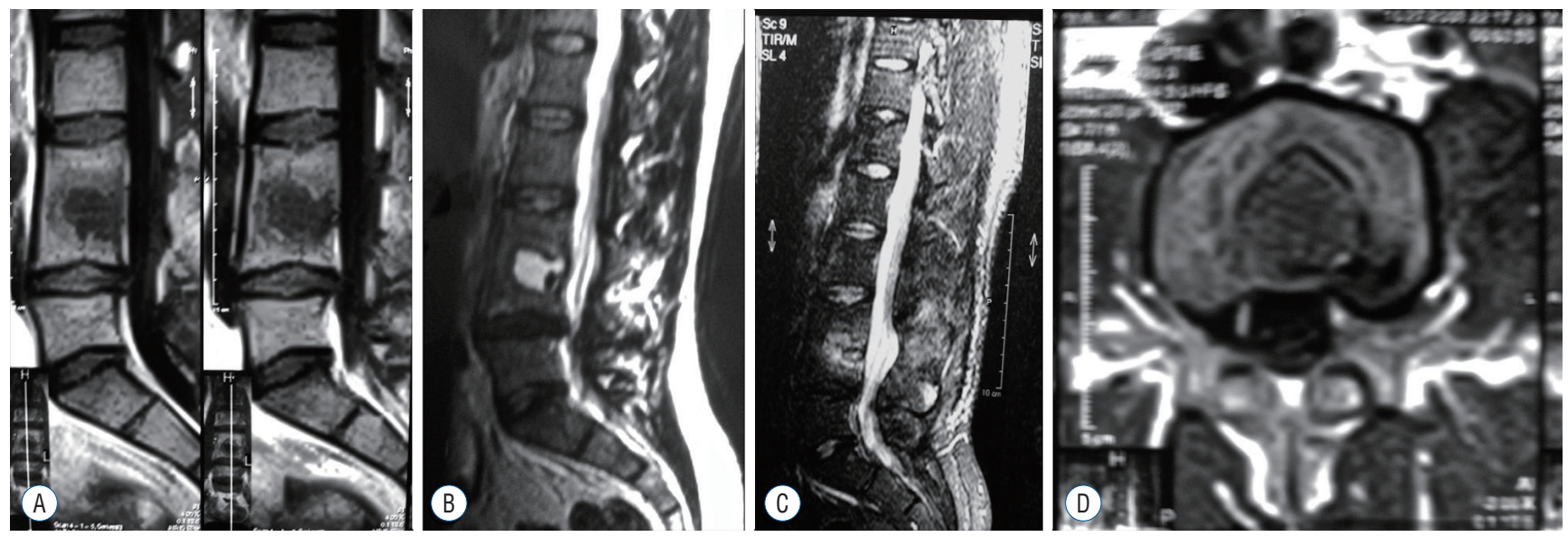

Fig. 3. A : Sagittal T1-weighted MRI image of lumbar spine demonstrated the fusion of anterior parts of $L 3$ and $L 4$ vertebral bodies and a hypointense lesion that lodged in posterior parts of disc space between these vertebrae.The lesion also expanded into the corpuses of these vertebrae. B : Sagittal T2-weighted MRI image of lumbar spine.The lesion was seen as hyperintense. C : Sagittal STIR sequence MRI image of lumbar spine. The lesion was seen as hyperintense. It is also seen a linear horizontal area of decreased signal intensity representing the intranuclear cleft in the center of posterior pars of disc space. D : Axial T1 weighted MRI image of lumbar spine at the level according to L4 vertebral upper end plate.

T1- (Fig. 3A, D) and hyperintense in T2-weighted (Fig. 3B) and STIR sequences (Fig. 3C) images. It was seen a linear horizontal area of decreased signal intensity representing the intranuclear cleft in the center of posterior part of disc space between fourth and fifth lumbar vertebrae in sagittal MRI image of the STIR sequence. The peripheral areas of the lesion were enhanced after gadolinium injection (Fig. 4).

The patient underwent L4-5 hemilaminectomy via a midline skin incision. There was not any adhesion in the extradural space and around the dura. A firm mass was found lodged in posterior part of the intervertebral disc space between the fourth and fifth lumbar vertebrae. There was not any epidur- 


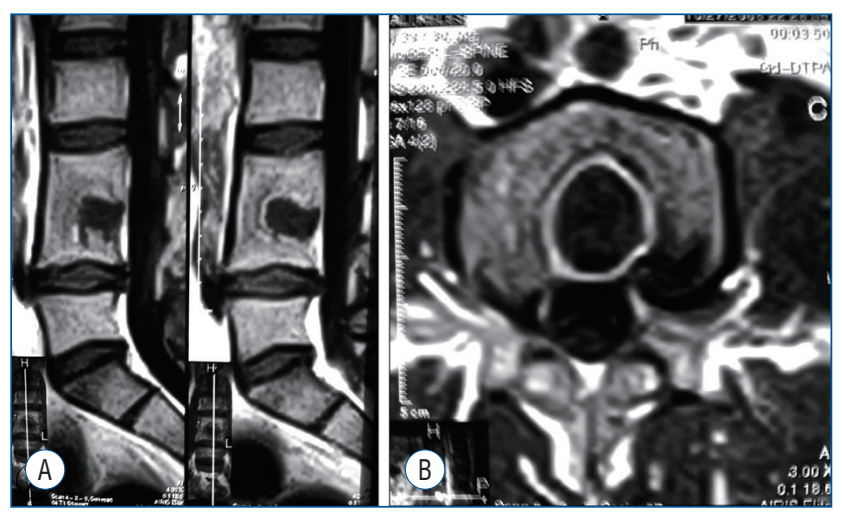

Fig. 4. A : Sagittal postcontrast T1-weighted image of lumbar vertebrae. A nodular enhancement around the peripheral areas of the lesion is seen. B : Axial postcontrast T1-weighted image. A marked enhancement around the peripheral areas of the lesion is seen.

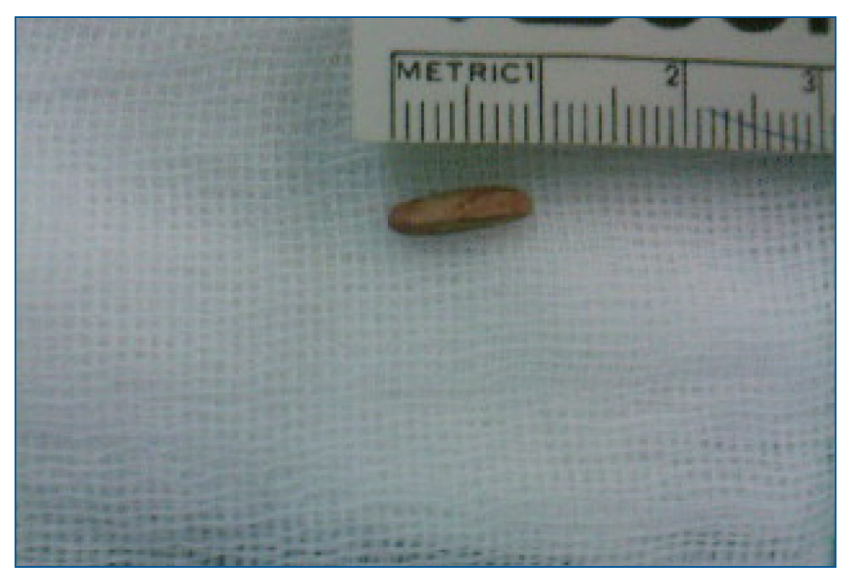

Fig. 5. The wooden foreign body removed from posterior part of disc space between fourth and fifth lumbar vertebrae.

al expansion of the mass. Excision of the mass revealed a tough granulation tissue surrounding a tiny piece of wood in a little cavity filled with a clear yellowish fluid (Fig. 5). The mass was totally removed. There was a fusion between anterior parts of third and fourth lumbar vertebrae and a degeneration in the discal material in the rest of intervertebral disc space. Chronic granulation tissue and a wooden splinter were confirmed histologically (Fig. 6, 7). Postoperatively, the pain resolved gradually and the patient was discharged without any problem 10 days after operation. He had a total symptomatic cure after two months from excision of the foreign body.

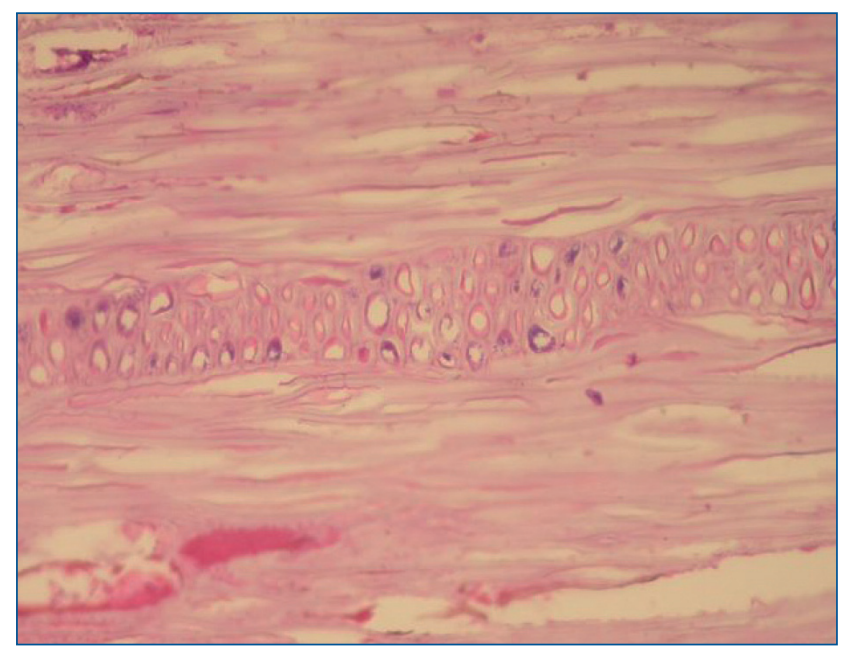

Fig. 6. The photomicrograph of wooden foreign body (H\&E $\times 200)$.

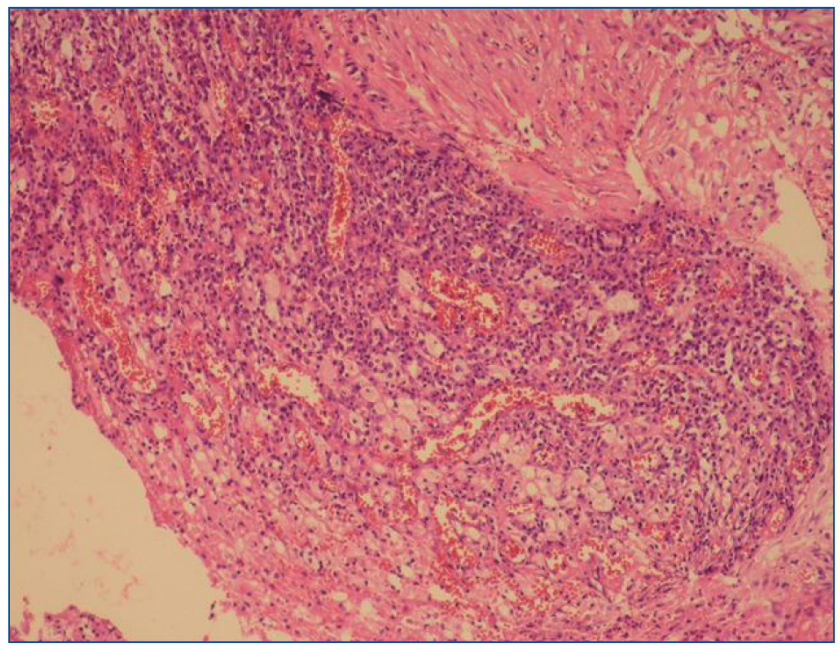

Fig. 7. Histopathological appearance of inflammatory granulation tissue surrounding the foreign body $(H \& E \times 200)$.

\section{DISCUSSION}

Biological responses of tissues to foreign bodies are influenced by the location and the nature of them ${ }^{1-7,10)}$. In a soft tissue, a wooden foreign body can cause either a mild inflammatory tissue reaction resulting in a localized granuloma or a severe reaction resulting in a significant infectious lesion with or without osseous reaction in adjacent bone ${ }^{1,4,6,8)}$.

Paraspinal disorders like ones in the intervertebral disc space may cause important complications because they may affect vital structures in and near the spinal canal. In a similar way, the majority of reported cases with foreign bodies that 
embedded and retained near the spinal canal presented with delayed symptoms or findings resulting from compression of neural elements due to developed granuloma or abscess as well as increased bony growths or migration of foreign body in the spinal canal $\mathrm{l}^{2,3,5-7,10,11)}$. In the literature, there are only four case reports presented with the retained foreign body granulomas in the intervertebral disc space from penetrant traumas $^{2,5,6,8,10)}$. All of them were from missile injuries mentioned previously. Two of these cases presented with cauda equina syndrome resulted from compression of neural structures due to granuloma and/or bony growths while two of them presented with symptoms and findings other than neurological deficits like our case ${ }^{2,5,6,8,10}$.

We thought that our patient's complaints probably were due to expanding of granuloma into the corpora of adjacent vertebrae. His complaints totally disappeared after removing the granuloma that in a way supported our thought.

The detection of wooden foreign bodies with plain radiographies and CT has limited value because they are radiolucent. Therefore, ultrasound and MR imaging are recommended in the detection of these foreign bodies like of other nonmetallic ones ${ }^{9}$. But, the identification of wooden foreign bodies may also be difficult on MR imaging when they are small and on ultrasound when they are in the deeper paraspinal tissues. Thus, a wooden foreign body in paraspinal tissues like intervertebral disc space may be easily missed especially in acute cases. Moreover, it is very difficult to predict the natural history of a retained foreign body in the intervertebral disc space, because, a sufficient number of cases is unfortunately not exist in the literature.

\section{CONCLUSION}

If a retained wooden body in intervertebral disc space is missed and it is not removed, it may be potentially hazardous and result in significant morbidity because of the nature of wood and the paraspinal location of intervertebral disc space. Moreover, a missed foreign body in a paraspinal tissues may cause further damages for patients and malpractice claims for physicians. Therefore, physicians and radiologist need to keep their diagnostic suspicions height in terms of retained foreign bodies during examination or follow up a patient with paraspinal wooden penetrant traumas.

\section{References}

1. Bouajina E, Harzallah L, Ghannouchi M, Hamdi I, Rammeh N, Ben Hamida R, et al. : Foreign body granuloma due to unsuspected wooden splinter. Joint Bone Spine 73 : 329-331, 2006

2. Conway JE, Crofford TW, Terry AF, Protzman RR : Cauda equina syndrome occurring nine years after a gunshot injury to the spine. A case report. J Bone Joint Surg Am 75 : 760-763, 1993

3. Daniel EF, Smith GW : Foreign-body granuloma of intervertebral disc and spinal canal. J Neurosurg 17 : 480-482, 1960

4. El Bouchti I, Ait Essi F, Abkari I, Latifi M, El Hassani S : Foreign body granuloma : a diagnosis not to forget. Case Rep Orthop 2012 : 439836, 2012

5. Grogan DP, Bucholz RW : Acute lead intoxication from a bullet in an intervertebral disc space. A case report. J Bone Joint Surg Am 63 : 1180-1182, 1981

6. Key JA : Foreign body arthritis. Surg Gynec Obstet $70: 897-902$, 1940

7. Kuijlen JM, Herpers MJ, Beuls EA : Neurogenic claudication, a delayed complication of a retained bullet. Spine (Phila Pa 1976) 22 : 910-914, 1997

8. Lunawat SK, Taneja DK : A foreign body in the spinal canal. A case report. J Bone Joint Surg Br 82 : 267-268, 2000

9. Peterson JJ, Bancroft LW, Kransdorf MJ : Wooden foreign bodies : imaging appearance. AJR Am J Roentgenol 178 : 557-562, 2002

10. Seroyer RN, Fortson $C H$, Theodotou CB : Delayed neurological sequelae of a retained foreign body (lead bullet) in the intervertebral disc space. J Bone Joint Surg Am 42-A : 595-599, 1960

11. Yoshioka K, Kawahara N, Murakami H, Demura S, Matsuda M, Tomita $\mathrm{K}$ : A glass foreign body migrating into the lumbar spinal canal : a case report. J Orthop Surg (Hong Kong) 20 : 257-259, 2012 